\title{
Ofensiva do capital e novas determinações do trabalho profissional
}

\author{
Mônica Maria Torres de Alencar \\ Universidade do Estado do Rio de Janeiro (UERJ)
}

Sara Granemann

Universidade Federal do Rio de Janeiro (UFRJ)

\section{Ofensiva do capital e novas determinações do trabalho profissional}

Resumo: Discute-se, neste artigo, as condições nas quais se realiza o trabalho profíssional dos assistentes sociais. Toma-se por fundamento "as configurações do trabalho na sociedade capitalista", as contrarreformas do Estado e as (in)consequentes alterações na natureza e na orientação das políticas sociais, conduzidas pelo grande capital em todo o mundo. Assim, a compreensão da pauperização da força de trabalho dos assistentes sociais ganha sentido na análise dos movimentos mais gerais da luta de classe e das necessidades do capital em se articular para garantir a realização de sua função primária, o aumento dos lucros.

Palavras-chave: ofensiva do capital, contrarreforma do Estado, trabalho profissional, precarização das condições de trabalho.

\section{Capital Offensive and the New Determinations of Professional Labor}

Abstract: This article discusses the conditions in which the professional work of social workers is conducted. It is based on the "configurations of labor in capitalist society," the counter reforms of the State and the (in)consequential alterations in the nature and orientation of social policies, conducted by the interests of capital throughout the world. Thus, the understanding of the impoverishment of the labor force of social workers takes on meaning in the analysis of the more general movement of class struggle and the needs of capital to organize to guarantee the realization of its primary function, the increase of profit.

Key words: capital offensive, counter reform of the State, professional labor, increased precariousness of labor conditions. 


\section{Introdução}

A preocupação com o trabalho do assistente social, como especialização do trabalho, inscrito na divisão social e técnica do trabalho social ganhou, nos últimos anos, fôlego renovado face às novas determinações históricas da sociedade contemporânea. Enquanto trabalho assalariado, a profissão não é imune à dinâmica dos processos sociais contemporâneos que determinam a sua configuração técnica-profissional, com claras implicações em suas competências e atribuições, bem como nas suas condições de trabalho.

Enquanto força de trabalho, inscrita na organização coletiva do trabalho, é permeável, ainda que disponha de uma relativa autonomia, aos condicionamentos e parâmetros institucionais e trabalhistas que se tecem no âmbito das instituições e organizações públicas e privadas, responsáveis pela gestão das "sequelas" decorrentes da ofensiva orquestrada pelo capital contra o trabalho. A ofensiva mais recente tende a articular respostas que apontam para a "assistencialização e financerização das políticas sociais" cujo significado parece ser o de administrar os efeitos do processo de desvalorização e superexploração do trabalho no capitalismo contemporâneo.

A contrarreforma do Estado e o aumento da exploração no âmbito da fábrica capitalista determinam o "empobrecimento" das políticas sociais e a redução dos direitos sociais da classe trabalhadora. As consequências das profundas alterações nas condições de trabalho, na forma de contrato da força de trabalho ocupada e na "gestão" da força de trabalho excedente determinam e atingem o trabalho do assistente social e a forma de contratação de sua força de trabalho, pois não há possibilidade de o trato da "questão social" ser aviltada e de, ao mesmo tempo, existirem condições generosas interferindo nesse processo. Nossa hipótese de trabalho é a de que "políticas sociais" aviltadas para a classe trabalhadora impõem o rebaixamento do contrato e das condições do trabalho profissional mediador/executor destas políticas sociais.

\section{Desvalorização e superexploração do trabalho no capitalismo contemporâneo}

Os processos históricos recentes de alteração na forma de produção e reprodução das relações capitalistas determinaram, em escala mundial, novas condições para o trabalho. Na particularidade históricosocial do capitalismo contemporâneo, em um contexto de acirramento da luta de classes, aprofundouse a desvalorização e a superexploração da força de trabalho para a continuidade da reprodução ampliada do capital. A potencialização das contradições intrínsecas à dinâmica da acumulação capitalista tor- nou-se mais evidente a partir dos efeitos da crise estrutural do capital na década de 1970 e das respostas articuladas pelo próprio capital, que levaram à reorganização econômica e política do sistema e à ofensiva generalizada contra o trabalho organizado.

A atual dinâmica do capitalismo mundial estrutura um conjunto de condições econômicas e políticas que aprofunda cada vez mais a tendência de desvalorização da força de trabalho à medida que modifica as formas de produção e o conjunto das relações sociais para assegurar o nível das taxas de lucro. A lógica da transnacionalização e da financeirização da economia, do desenvolvimento científico e tecnológico modificou a produção de bens e serviços com implicações na organização e gestão do trabalho. Dentre as principais consequências, situam-se as alterações no processo produtivo, agora caracterizado pelas flexibilização e descentralização da produção em que a terceirização assume grandes proporções. Nesse cenário, são reeditadas formas pretéritas de trabalho, como, por exemplo, o trabalho por peça e domicciliar, além do predomínio de regimes de trabalho em contrato temporário e jornada de trabalho parcial.

Embora as reestruturações econômicas e políticas com impactos no trabalho sejam próprias da dinâmica do capital, não sendo, portanto, novidade histórica, há que se considerar as condições nefastas que atualmente conferem para a força de trabalho. Ao tomar-se em conta o fato de que a mais recente crise do capital apresenta elementos novos, de acordo com Mészáros (2002), dado seu caráter universal, seu alcance global, sua escala de tempo extensa, contínua e permanente, a ofensiva contra o trabalho adquire conotações extremas cujo principal sentido é a sua mais completa subjugação.

As exigências da produção têm como escopo o uso mais intensivo da força de trabalho, para viabilizar ganhos permanentes de produtividade em um ambiente de reduções de custo e aumento na maleabilidade do processo produtivo, face às recorrentes mudanças no nível e na composição da demanda, bem como a incorporação das inovações tecnológicas. O movimento de reprodução ampliada do capital rompe com essa "camisa de força" criada pela consolidação de certo padrão de organização produtiva e social, por meio da incorporação de novos equipamentos informatizados, desverticalização das empresas, relocalização de plantas e pela reorganização das formas de regulação do trabalho.

A crescente flexibilidade produtiva passou a exigir a intensificação do uso do trabalho o qual, para existir, deve ter por base também as modificações em suas relações. Passou-se a questionar as formas de organização das relações de trabalho que, baseadas na estabilidade do contrato e na jornada préestabelecida, ao serem implementadas no mundo todo, tornaram frágeis as amplas conquistas do mo- 
vimento operário. Tais conquistas - ainda que limitadas na direção de superar o modo de produção capitalista - punham limites ao uso dilapidador da mão de obra, abriam a possibilidade de ampliar o emprego e regulamentavam a incorporação social do trabalho.

Com a racionalização da produção, opera-se a reorganização das relações de trabalho que tem implicado, na verdade, na instauração de uma nova correlação de forças entre o capital e o trabalho; nela, o primeiro passa a ter um maior poder na determinação da forma de uso do trabalho (referentes à alocação, à remuneração e ao tempo de trabalho) e potencializa, inclusive, o seu uso de forma mais intensiva. A flexibilização e a desregulamentação das relações de trabalho têm um significado bastante expressivo que é o de desvencilhar o capital da "camisa de força" proporcionada pelo arranjo regulador, cujo eixo estava pautado por uma forte intervenção do Estado em uma significativa oposição aos princípios que colocam no mercado a determinação do uso do trabalho.

Trata-se, de fato, da ruptura de um padrão de regulação social do mercado e das relações de trabalho que, sob a égide da desregulamentação econômica e social, do imperativo da competitividade, da exponenciação da lógica do mercado, restabelecem a autonomia das empresas na contratação e na determinação das regras de uso da força de trabalho. A atual etapa do capitalismo, com o uso destrutivo da força de trabalho, reedita condições e relações de trabalho que remontam ao século $19^{1}$. Repõem-se, no capitalismo atual, traços do que Burawoy (1990) denominou de "regime despótico", no qual prevalecia a gestão privada do uso do trabalho pela coação econômica do mercado que instaura o "despotismo hegemônico"2.

Tal processo coaduna-se com a atual fase de acumulação capitalista, caracterizada pelo predomínio do capital financeiro, pela reorganização econômica e produtiva e por políticas sob hegemonia liberal que flexibilizam as relações de trabalho com a finalidade de fortalecer uma regulação privada das relações entre o capital e o trabalho. Portanto, as transformações no sistema de relações de trabalho fazem parte de um movimento mais amplo de reestruturação capitalista, em contraposição ao padrão de desenvolvimento socioeconômico hegemônico no pós-guerra e ao sistema de regulação das relações de trabalho, tanto do ponto de vista institucional como da dinâmica das negociações coletivas.

A produção recente de um desmesurado contingente de trabalhadores considerados supérfluos, excedentários ou sobrantes deve ser relacionada à dinâmica atual do capitalismo contemporâneo que assumiu expressões diferenciadas, sobretudo, a partir da crise estrutural do capital evidenciada mais fortemente no início da década de 1970, quando desencadeou um profundo reordenamento das bases econômicas, sociais e políticas da trajetória histórica do capitalismo fundada no pós-Segunda Guerra Mundial.

O ressurgimento atual do desemprego, enquanto um fenômeno crônico e global, é apenas a ponta de um iceberg. A cultuada política do "pleno emprego" dos anos de ouro do capitalismo não nos deve fazer esquecer: tais políticas foram bastante localizadas nos países do centro do capitalismo onde o desemprego foi controlado por um período e para parcelas de trabalhadores. Na periferia do modo de produção capitalista e para expressivas frações da classe trabalhadora no centro do modo de produção, por exemplo, para os imigrantes das ex-colônias europeias, o "pleno emprego" nunca foi uma possibilidade. Na realidade, o desemprego é a expressão de um processo muito mais amplo no campo do embate entre o capital e o trabalho e constitui o modo de ser desta relação. Nos últimos 30 anos é, pois, a expressão privilegiada da ofensiva do capital sobre o trabalho. Não se pode deixar de considerar que as bases desse processo estão profundamente relacionadas à dinâmica histórica do capitalismo que se consolidou principalmente nos anos que se seguiram à Segunda Guerra Mundial.

O novo desenvolvimento do capitalismo mundial confere um novo sentido à categoria de população "excedente", à medida que não possui mais a capacidade de absorver o contingente de trabalhadores que está à procura de empregos. Alves (2000) tem razão quando afirma que ocorre uma alteração lógico-epistemológica (e ontológica) da categoria "população trabalhadora excedente". Isto é, o que durante a grande indústria poderia ser considerado "trabalhadores assalariados excedentes" converte-se no atual momento histórico em "população trabalhadora excluída". As imensas massas de desempregados, incluindo o chamado "subproletariado tardio", representam os novos excluídos da "nova ordem capitalista". Alves considera esta parcela da classe trabalhadora tão importante para a nova ordem do capital, quanto o próprio desemprego estrutural.

A lógica do capitalismo, atualmente potencializada, é a de expulsar o trabalho vivo do processo de trabalho como estratégia de valorização do capital. Nesse caso, reproduz-se hoje na lógica estrutural do capital uma massa de trabalhadores que, de fato, torna-se excluída do processo de trabalho, tendo pouca ou quase nenhuma chance de inserir-se novamente no circuito do grande capital, restando-lhes apenas as ocupações contingentes. Para Alves, o "excedente" interverte-se em "excluído". Desse modo, surgem os novos excluídos da "nova ordem capitalista", que são as massas de desempregados (e subproletários) do sistema de exploração do capital (ALVES, 2000, p. 76).

Se a produção progressiva de uma superpopulação relativa não se configura como algo episódico na his- 
tória do capitalismo, a novidade histórica é que a dinâmica de acumulação do capital repõe, hoje e em escala ampliada, a tendência intrínseca e contraditória do processo de acumulação do capital de produzir uma parcela de força de trabalho "sobrante", emprestando um novo significado ao exército de reserva de trabalhadores. Para Mészáros (2002), a questão do desemprego não se limita mais apenas à existência de um "exército de reserva", com a possibilidade de ser ativado nos momentos de ascensão econômica do sistema. Para esse autor, o desemprego assumiu um caráter crônico e global e, por isso mesmo, tornou-se uma força potencialmente explosiva denotando um limite absoluto do capital.

\section{[...] como uma grande ironia da história, a dinâmica interna antagonista do sistema do capital agora se afirma - no seu impulso inexorável para reduzir glo- balmente 'o tempo de trabalho necessário' a um valor mínimo que otimize o lucro - como uma ten- dência devastadora da humanidade que transfor- ma por toda parte a população trabalhadora numa 'força de trabalho crescentemente supérflua' (MÉSZÁROS, 2002, p. 341, grifos do autor).}

Para este autor, está-se diante de um ataque em duas frentes à classe operária em todo o mundo que se revela no desemprego crônico em todos os campos de atividade, disfarçados como práticas trabalhistas flexíveis, eufemismo para a política deliberada de fragmentação e precarização da força de trabalho e para a máxima exploração administrável do trabalho em tempo parcial, e também se revela numa redução significativa do padrão de vida até mesmo dos trabalhadores em ocupações de tempo integral. No entanto, o reconhecimento da existência dessa população sobrante, redundantes para as requisições do capital estão longe de poder ser consideradas supérfluas como consumidoras que asseguram a continuidade da reprodução ampliada e da autovalorização do capital. Para ele, essa força de trabalho supérflua continua mais necessária do que nunca para possibilitar a reprodução ampliada do capital (MÉSZÁROS, 2002).

Sendo este sistema uma poderosa estrutura "totalizadora" de controle, à qual tudo deve se ajustar, que se sobrepõe a tudo e a todos, no capitalismo contemporâneo essa tendência assume cada vez mais uma lógica essencialmente destrutiva, cuja máxima expressão atual esta determinada pelo que Mészáros (2002) denomina de "taxa de utilização decrescente" do valor de uso das coisas. Esta afeta negativamente todas as três dimensões fundamentais da produção e do consumo, os bens e serviços, as instalações e maquinaria e a própria força de trabalho. A taxa de uso decrescente se manifesta: na obsolescência planejada em relação aos bens de consumo duráveis produzidos em massa; na substitui- ção, no abandono ou aniquilamento deliberado de bens e serviços; no crescente desperdício resultante da introdução de tecnologia nova; e na subutilização crônica de instalações e maquinário.

Quanto à força de trabalho, a tendência de utilização decrescente relativa à do trabalho socialmente disponível constitui-se, para Mészáros, a contradição mais explosiva do capital. Na verdade, para esse autor, está-se diante de uma "contradição antagônica e literalmente explosiva", qual seja: por um lado o capital necessita crescentemente de consumidores de massa, de outro tem uma necessidade sempre menor de trabalho vivo. Mas, ocorre que o trabalho não é apenas "fator de produção", mas também o "consumidor de massa", constituindo-se, pois, numa identidade estrutural que está na base da economia capitalista, conferindo ao trabalho uma objetiva posição estratégica no sistema. Esta tendência estrutural não pode ser resolvida por intermédio de medidas conjunturais. A moderna teoria econômica burguesa, ao buscar reduzir o papel estratégico do trabalho a um mínimo irrelevante, inventa o consumidor e o produtor, este último, o capitalista, legitima a mais antissocial e desumanizadora tendência do capital para a eliminação brutal do trabalho vivo do processo de trabalho.

Os processos de transformações na dinâmica do capitalismo orientam-se, pois, por uma clara perspectiva de classe revelando-se como uma ofensiva do capital contra o trabalho assalariado, que emerge nesse processo ainda mais "complexo, fragmentado e heterogeneizado". O desemprego contemporâneo, de escala planetária, relaciona-se à nova dinâmica do capital para a superação de sua própria crise, inscrevendo-se ainda numa dinâmica que tenta repor, em novos patamares, a dominação do capital sobre o trabalho. O desemprego e a precarização do trabalho tornam-se armas contra os trabalhadores, com o sentido de debilitar seu potencial de classe. O objetivo é propiciar as bases favoráveis à valorização do capital e assegurar as condições favoráveis para a recomposição da mais-valia. Nesse caso, ainda é possível reconhecer a funcionalidade de uma população trabalhadora excedente nas novas estratégias de dominação do capital, sob as novas configurações históricas que remodelam o cenário do capitalismo.

Em síntese a nova ofensiva do capital configurase não apenas pelas determinações tecnológicas, mas também por determinações políticas que são o resultado sócio-histórico da luta de classes, do amadurecimento das contradições geradas ao longo do processo de internacionalização das relações capitalistas de produção no período histórico de 1945 à 1968/ 1970; e envolvem elementos econômicos e sociopolíticos. Nesse caso, as respostas efetuadas pelo capital em relação à crise têm uma clara dimensão de classe, na medida em que o capital tem o ob- 
jetivo de, além da retomada das taxas de lucro, fragilizar a auto-organização dos trabalhadores e com isso retomar e aprofundar o controle sobre eles.

\section{Estado, políticas sociais aviltadas e rebaixamento do valor da força de trabalho}

No âmbito da articulação de respostas às crises do capital e da retomada das taxas de lucro, o Estado continua a jogar papel central, mas desuniforme em relação ao período histórico dos anos posteriores ao segundo conflito bélico mundial até a década de 1970, os chamados anos de ouro do capitalismo. Naquelas décadas, o estágio da luta de classes, a existência da vitoriosa União das Repúblicas Socialistas Soviéticas, responsável pelo fim da barbárie nazifascista da Segunda Grande Guerra Mundial e as condições ótimas de lucro para o capital, decorrentes da necessidade de reconstrução da parte do mundo destruída pela máquina bélica, possibilitou também que partes significativas da classe trabalhadora tivessem acesso a níveis de proteção social inéditos sob o capitalismo.

Esgotadas tais condições novos arranjos são indispensáveis à manutenção da taxa de lucro do capital e ao Estado cumpre prover as circunstâncias de um novo período de crescimento. Ao Estado, o novo estágio da acumulação capitalista requereu contrarreformas no sentido de privatizar o fundo público de diferentes e criativas formas, dentre as quais situam-se a:

a) entrega do parque estatal lucrativo (produtivo e de serviços) aos negócios privados;

b) redução da proteção à força de trabalho ocupada e excedente pela diminuição de direitos trabalhistas e sociais de que são exemplos característicos as contrarreformas previdenciárias, trabalhista e sindical;

c) redefinição do campo de atuação das políticas sociais como atividades não exclusivas do Estado de modo a torná-las serviços privados, esferas passíveis de comercialização, de criação de novos negócios e de intensificação dos já existentes (por exemplo a saúde, a previdência e o ensino privado) com subsídios do fundo público;

d) canalização de parte mínima dos recursos do fundo público que financia as políticas sociais de responsabilidade do Estado para a fração da classe trabalhadora mais pauperizada (programas de transferência de renda/assistenciais, curiosamente cognominados "bolsas"), a enorme fração excedentária da força de trabalho, pela via de operação monetarizada, com dinheiro plástico, operado por bancos, de modo a tornar o recurso público ${ }^{3}$ também recursos monetários manipulados por instituições ban- cário-financeiras, no interesse do grande capital portador de juros;

e) imputação à força de trabalho empregada pelo Estado da responsabilidade pela ineficiência dos serviços públicos para impor similares condições de trabalho e de vida, de contrato rebaixado, de instabilidade no trabalho e de redução de direitos trabalhistas e sociais às praticadas nas empresas capitalistas contra a força de trabalho. Para a consecução destas medidas é indispensável alterar em profundidade o aparelho estatal e criar novos entes jurídicos "estatais". Tais entes em geral carregam do público apenas a denominação porque sua natureza é essencial e profundamente privada. Tais "instituições" viabilizam as parcerias público-privadas e se metamorfoseiam em distintas formas, conforme os embates de classes em cada espaço e local, das quais as mais comuns são as "fundações estatais de direito privado", as "organizações sociais (OS)", as "organizações da sociedade civil de interesse público (OSCIP)"'e as “fundações de apoio" etc.

A nova configuração assumida pelo Estado não descuidou de reforçar os aparatos repressivos/policiais ${ }^{4}$ contra os movimentos sociais da classe trabalhadora e passou a criminalizar a pobreza e suas ações reivindicativas por melhores condições de vida e trabalho em todo o mundo, embora com mais 'afinco' nos países da periferia do capitalismo como meio de combater a auto-organização dos trabalhadores. Como analisou Marx, em passagem sobre os expedientes da burguesia para elevar a exploração da força de trabalho,

Para atingir esse objetivo, para extirpar a preguiça, a licenciosidade e as divagações românticas da liberdade, para reduzir a taxa arrecadada em benefício dos pobres, para incentivar o espírito industrial e para reduzir o preço do trabalho nas manufaturas, propõe esse fiel paladino do capital o meio eficaz, a saber, encarcerar os trabalhadores que dependam da beneficência pública, em uma palavra, os pobres, num 'asilo ideal de trabalho'. 'Será mister transformar esse asilo em casa de terror'. Nessa 'casa de terror', nesse asilo ideal de trabalho, haverá a obrigação de trabalhar ' 14 horas por dia, incluindo-se o tempo adequado para as refeições, de modo que restarão 12 horas inteiras de trabalho' (MARX, 1988, p. 314, grifos do autor).

Às contrarreformas do Estado somaram-se as inovações tecnológicas e as mudanças no método de trabalho que oportunizaram a elevação da exploração da força de trabalho (instabilidade e precarização do trabalho, extensão da jornada de trabalho, aumento do trabalho excedente, redução dos direitos traba- 
lhistas e sociais), requerida pelo capital para exponenciar sua lucratividade.

Em tal cenário, as diferentes frações da classe trabalhadora - quer vendam sua força de trabalho ao Estado ou diretamente ao capital - sofreram forte ofensiva na forma de contratação e venda da força de trabalho, na piora das condições de vida e de trabalho, talvez a mais grave dos últimos dois séculos.

Cumpre notar, todavia: as investidas do capital foram maiores ou menores, mais ou menos intensas e profundas, conforme a capacidade de reação e de organização demonstrada pela classe trabalhadora nos diferentes quadrantes do planeta, mas, sem exceção, a redução dos direitos e a reformulação das condições gerais do contrato de trabalho - inclusive com o surgimento de formas análogas ao trabalho escravo em vários países do mundo - são as condições basilares para a elevação das taxas de lucro.

$\mathrm{O}$ aumento do desemprego e da pauperização absoluta de significativos contingentes da força de trabalho pelo mundo ensejou ao grande capital - por meio de seus organismos multilaterais, espécie de capital coletivo transnacionalizado - demarcar uma forma específica de proteção social. Forma esta que não pôde seguir outros cânones a não ser exatamente os mesmos operados pelo capital no trato dispensado para a força de trabalho em geral: redução dos limites sociais da reprodução social do trabalho para torná-los os mais agudos e regressivos possível; preferencialmente ao resumir o ser social ao âmbito do ser natural e de suas muito básicas necessidades físicas. No universo de formulações do Estado do grande capital para a "proteção social" a redução ao ser biológico, natural é bastante visível em políticas e programas de "transferência de renda" como o "Bolsa Família".

A precarização, a instabilidade do não direito, a fragmentação da "questão social", a responsabilização do sujeito individual por seu lugar na vida social, a "política social" diferenciada para as frações da força de trabalho ocupada e excedente - regra geral, sempre rebaixadas e insuficientes - são feições do mesmo estágio do desenvolvimento capitalista.

Não é demais lembrar que neste quadro aprofundase a alienação do trabalho e aumenta a exploração porquanto ser "impulso imanente e tendência constante do capital elevar a força produtiva do trabalho para baratear a mercadoria e, como consequência, o próprio trabalhador" (MARX, 1988, p. 367).

\section{Condição do trabalho profissional na sociedade brasileira contemporânea}

Historicamente o Congresso Brasileiro de Assistentes Sociais (CBAS) tem sido espaço de expressão e discussão do projeto profissional nas suas dimensões teóricas, práticas-interventivas e ético-políticas. Ao mesmo tempo revela-se como importante termômetro da dinâmica do mercado de trabalho profissional ao dar a conhecer tensões e contradições do trabalho profissional nos diferentes espaços ocupacionais, guardadas suas naturezas, racionalidades e finalidades distintas.

O estudo dos relatórios da sessão temática Trabalho profissional e espaços socioocupacionais ${ }^{5}$ dos três últimos congressos explicitou importantes elementos relacionados aos feixes de tensões e contradições que perpassam a malha organizacionalinstitucional empregadora dos assistentes sociais com repercussões no trabalho profissional. As mudanças em curso no campo da orientação e da natureza da política social no Brasil repercutem no espaço de trabalho do assistente social à medida que determinam, em última instância, as condições em que o trabalho profissional se realiza quanto requisições, normatização, delimitação de funções e atribuições e normas contratuais (salário, jornada de trabalho) (IAMAMOTO, 2007).

Por intermédio do relato e da problematização das experiências profissionais tornam-se evidentes as mudanças processadas nas agências empregadoras dos assistentes sociais quanto à orientação e natureza das políticas sociais. No contexto social brasileiro, sob o discurso da crise econômica e da escassez de recursos, tendem a ser estruturadas ações que ferem a condição de direito das políticas sociais de caráter universalista. As orientações da política social em geral e da assistência social em particular fundamentam-se, para a força de trabalho que as executam, com fortes traços e tendências de precarização, focalização e descentralização, e, nesse quadro, as atividades filantrópicas e voluntárias e os novos "entes" do estado brasileiro tornam-se parceiros importantes e, supostamente, ajudam a tecer a "gestão da pobreza". Some-se ainda a numerosa gama de variantes da privatização da seguridade e das políticas sociais e de assistência que passam a ser alocadas no mercado, quando passíveis de lucro, e/ou na sociedade civil, pela 
transferência de partes do fundo público para a intervenção privada sob a "questão social".

Aprofunda-se, pois, a tendência já sinalizada por Mota (1995) acerca da condição da seguridade social no Brasil de privatização, como é o caso da previdência e saúde, que se conjuga com o assistencialismo focalizado sobre os segmentos mais pobres. O que tem implicado a carência de recursos, a estruturação de uma plêiade de programas sociais voltados para os segmentos sociais mais vulneráveis, a tendência de "assistencialização das políticas sociais" e, mais grave, pela "financeirização" do fundo público. Com a expansão desta segunda tendência, reduzem-se os postos de trabalho típicos da era em que o grande capital suportou a construção do Estado de bem-estar social com políticas universais, grandes equipamentos públicos sob sua execução direta e com um número significativo de força de trabalho por ele empregada para viabilizar os direitos sociais e trabalhistas. Todavia, a vigência de uma tal realidade deve ser submetida a um novo momento de necessidade de aumento das taxas de lucro.

Ao capital financeiro e portador de juros interessam as mais diferentes formas de apropriação do fundo público, isto é, das generosas quantidades de mais valia produzidas pela força de trabalho que sustentam as intervenções do Estado capitalista. Já não lhes bastam, aos grandes capitais, no presente estágio da vida social, os empréstimos, as privatizações, os favores licitatórios e toda a numerosa sorte de "serviços" prestados ao grande capital por seu "comitê executivo". Assim, é parte importante da apropriação do fundo público pelo grande capital, na sua forma bancáriofinanceira, as medidas e as políticas de "transferência de renda" para as frações mais pauperizadas da classe trabalhadora. Tais instituições bancário-financeiras ao intermediarem as "transferências de renda" para a fração mais miserável da classe trabalhadora realizam a sua função por excelência: multiplicar o mesmo dinheiro e torná-lo capital ${ }^{6}$.

Reconhecer os traços da assistencialização e da financeirização das políticas sociais é distinguir as profundas e irreconciliáveis contradições do tempo presente que no espaço da proteção social nos confrontam com limites muito claros, porque de classe. Desvelar estes limites é fundamental para a compreensão das metamorfoses do trabalho profissional; mascarálos é tornar indecifrável a precarização do trabalho dos assistentes sociais, o elevado grau de sofrimento e frustração manifestos em reflexões nos ambientes profissionais e de organização da categoria, a dilatação e a intensificação da jornada de trabalho, a decadência geral das condições de vida e de trabalho.

Toda essa dinâmica configura uma nova realidade profissional à medida que a tendência de privatização e pauperização da política social face às exigências da contrarreforma do Estado brasileiro são objetivadas no âmbito institucional-organizacional responsáveis pela sua operacionalização e execução. Os impactos para o trabalho profissional são imediatos e fortemente condicionados pelos parâmetros institucionais, dadas as exigências colocadas pelas agências empregadoras e pela realidade do formato do conjunto de programas sociais. Não se pode perder de vista que se trata de diferentes espaços ocupacionais e, certamente, a lógica da pauperização e privatização dos serviços têm expressões diferenciadas na medida em que se trata também de natureza, racionalidades e finalidades institucionais distintas.

Sob as racionalidades técnico-políticas e administrativas, próprias da contrarreforma do Estado brasileiro, teceram-se condições para o exercício profissional com fortes tendências de precarização e de alienação profissional. No atual contexto histórico regressivo para os direitos dos trabalhadores, a barbárie social, através de mediações específicas, reproduz no âmbito institucional do trabalho profissional condições limitadas para a autonomia teórico-metodológica, técnica e ético-política do exercício profissional. Isto significa afirmar o necessário debate que problematiza os traços singulares de autonomia relativa da profissão no quadro da correlação de forças dos dias presentes. Para Iamamoto (2007, p.128), "estabelece-se a tensão entre projeto ético-político e alienação do trabalho, indissociável do estatuto assalariado."

A tendência, pois, de alienação do trabalho está enraizada nas condições de trabalho propiciadas pelo estágio atual do modo de produção, por suas exigências de lucro, pelas contrarreformas de seu Estado, pela redefinição das políticas sociais com ênfase nos seus traços de assistencialização e financeirização. Sobre tais elementos, repousam muitas das problematizações dos assistentes sociais quando se referem ao sofrimento e ao desgaste mental e emocional, ao desânimo face às normas e aos parâmetros institucionais, as (im) possibilidades de operacionalizar seus princípios ético-políticos, a inserção combinada em várias políticas sociais que impõe rotinas de trabalho duplas, sob a perspectiva do cumprimento de índices de produtividade e de metas a serem alcançadas e atestadas.

Como o indicou Lukács, o processo de conhecimento da vida social sob o modo de produção capitalista na idade presente torna-se mais difícil porque o fetiche do capital impregna as relações sociais de modo profundo, como o próprio modo de ser e de se realizar do estágio em curso. Na sua letra,

Eis como a evolução do capitalismo no estágio imperialista não faz senão intensificar o fetichismo geral, pois, o fato da dominação do capital financeiro, os fenômenos a partir dos quais seria possível desvendar a 'reificação' de todas as relações humanas, tornam-se cada vez menos acessíveis à 
reflexão da média das pessoas (LUKÁCS, 1967, p. 29 , grifos no original).

Foi o estatuto deste profissional assalariado que circunscreveu o universo e as condições nas quais se realiza o trabalho profissional do assistente social. Estas condições são aqui sumariadas como traços indicativos e, ainda, que carecem de quantificação como objeto de pesquisa de muitos para que seja possível que a universidade e a categoria, autonomamente, possam fazer a crítica e a superação dos fetiches que também nos alcançam em tempos tão bárbaros.

A sistematização, a seguir, foi elaborada pela autoras com base em relatórios de CBAS: Sessão Temática: Trabalho profissional e espaços sócioocupacionais:

\section{Formas de contratação da força de trabalho profissional \\ - Contratos sem realização de concursos; \\ - Contratos por prestação de serviços; \\ - Consolidação das Leis do Trabalho (CLT).}

\section{Expressões da precarização do trabalho profissional}

- Trabalho domiciliar;

- Legalização da precarização no âmbito municipal;

- A instabilidade e a precarização do trabalho dos assistentes são identificadas desde os editais dos concursos pela ausência de dados sobre como será o trabalho e as condições de contratação da força de trabalho.

\section{Condições do trabalho profissional}

- Metas de produtividade e desempenho são campo fértil para o assédio moral quando não se alcançam as metas;

- Atuação na interseção de duas ou mais políticas sociais;

- Exigências de múltiplas capacitações para trabalhar com diferentes áreas da política social ao mesmo tempo;

- Trabalho solitário e individual;

- Jornadas longas e intensivas;

- Baixos salários;

- Exploração e fragmentação do trabalho;

- Rotinas de viagens exaustivas;

- Acúmulo de funções e atividades, como participar em diversos conselhos e em cada um desenvolver e representar uma categoria (gestor, trabalhador);

- Superposição das funções;

- "Assistencialização": rebaixa o direito do usuário e precariza as condições de contrato e das condições de trabalho dos assistentes sociais, principalmente nos municípios;
- Trabalho profissional é produtor de sofrimento e de desgaste emocional (assistência/abrigos).

As reflexões iniciais aqui desenvolvidas permitem afirmar que as condições de trabalho dos assistentes sociais pioraram nas décadas de 1990 e de 2000 e seguiram igual tendência auferida em estudos de outras categorias profissionais, em particular, e na classe trabalhadora como um todo. Todavia investigações amiúde são mais do que necessárias para capturar e problematizar as tendências centrais nestes quase 20 anos de contrarreformas do Estado e das políticas sociais. $\mathrm{O}$ aprofundamento da pesquisa neste campo certamente contribuirá para o desvanecimento de perspectivas ilusórias sobre os potenciais das políticas sociais, bem como para compreender a condição histórica do trabalho dos profissionais nelas envolvidos.

\section{Referências}

ALVES, G. O novo (e precário) mundo do trabalho. Reestruturação produtiva e crise do sindicalismo. São Paulo: Boitempo/Fapesp, 2000.

BURAWOY, M. A transformação dos regimes fabris no capitalismo avançado. Revista Brasileira de Ciências Sociais, v. 5, n. 13, p. 29-50, jun. 1990.

ENGELS, F. A situação da classe trabalhadora na Inglaterra. Prefácio de José Paulo Netto. Tradução de B. A. Schumann. São Paulo: Boitempo, 2008.

IAMAMOTO, M. Serviço Social em tempo de capital fetiche. São Paulo: Cortez, 2007.

IANNI, O. A ditadura do grande capital. Rio de Janeiro: Civilização Brasileira, 1981.

LUKÁCS, G. Existencialismo ou marxismo. São Paulo: Senzala, 1967.

MARX, K. O capital. Crítica da Economia Política. Livro 1: O processo de produção do capital. Volume 1. Rio de Janeiro: Bertrand Brasil, 1988.

. O capital. Crítica da Economia Política. Livro 3: O processo global de produção capitalista. Volumes IV, V, VI. Rio de Janeiro: Bertrand Brasil, 1988a.

MÉSZÁROS, I. Para além do capital. Tradução de Paulo Cezar Castanheira e Sérgio Lessa. São Paulo: Boitempo, 2002.

MOTA, A. E. Cultura da crise e seguridade social: um estudo sobre as tendências da previdência e da assistência social brasileira nos anos 80 e 90. São Paulo: Cortez, 1995. 
PAULO NETTO, J. Capitalismo monopolista e Serviço Social. São Paulo: Cortez, 1991.

\section{Notas}

1 Para um quadro tocante das condições presentes no século 19, é suficiente conferir a excepcional obra de Engels (2008).

2 O novo despotismo é a tirania "racional" da mobilidade do capital sobre o trabalhador coletivo. A reprodução da força de trabalho é novamente vinculada ao processo de produção, mas em vez de se dar pela via individual, a ligação se produz no nível da empresa, região ou mesmo nação. O medo de ser despedido é substituído pelo medo da fuga de capitais, do fechamento da fábrica, da transferência das operações e do desinvestimento na planta industrial.

3 Ao analisar as funções do Estado sob a idade dos monopólios, a lúcida crítica de José Paulo Netto (1992, p. 21-) indica: as funções extraeconômicas ou políticas implicam em, contraditoriamente e pela mesma ação, contemplar as requisições do capital na garantia de lucros e na criação de espaços de inversões e, também, a da força de trabalho no atendimento de demandas por meio de políticas sociais que se configuram em respostas fragmentadas e individualistas para a "questão social".

4 Não é demais lembrar: naAmérica do Sul e em outros cantos do planeta as ditaduras do grande capital foram a forma de expansão dos monopólios quando se anunciava o fim dos anos de ouro na Europa pós Segunda Grande Guerra Mundial. VerIanni(1981).

5 As autoras agradecem as entidades da categoria e estudantil (Conjunto Cfess/Cress, Abepss, Enesso) organizadoras dos CBAS pela oportunidade, nos três últimos congressos, da leitura dos trabalhos e o privilégio de coordenar sessões. De modo especial, somos gratas aos autores dos trabalhos que nos possibilitaram elementos para a problematização das polêmicas aqui postas.

6 É muito elucidativo e de extrema relevância em tempos de crise mundial a leitura do livro 3 de O Capital (MARX, 1988a). Ali, colhemos as inspirações para pensar a financeirização das políticas sociais.

\section{Mônica Maria Torres de Alencar}

monicatalencar@hotmail.com

Doutorado em Serviço Social pela Universidade Federal do Rio de Janeiro (UFRJ)

Professora da Faculdade de Serviço Social da Faculdade de Serviço Social da Universidade do Estado do Rio de Janeiro (UERJ)

Professora pesquisadora do Centro de Estudos Octávio Ianni (CEOI)

\section{Sara Granemann}

sgranemann@uol.com.br

Doutorado em Serviço Social pela Universidade Federal do Rio de Janeiro (UFRJ)

Professora Adjunto da Escola de Serviço Social da UFRJ.

Pesquisadora do NEPEM-UFRJ (Núcleo de Estudos e Pesquisas Marxistas).

\section{UERJ - Faculdade de Serviço Social}

Rua São Francisco Xavier, n. 524

Maracanã

Rio de Janeiro - Rio de Janeiro - Brasil

CEP: 20550-011

\section{UFRJ - Escola de Serviço Social}

Av. Pasteur 250 - Fundos

Campus Praia Vermelha

Botafogo

Rio de Janeiro - Rio de Janeiro - Brasil

CEP: 22290-240 